\title{
Electrochemical migration of Sn and Ag in NaCl environment
}

\author{
Bálint Medgyes, Dániel Szivós, Sándor Ádám, Lajos Tar, Patrik Tamási, László Gál, Richárd Berényi and Gábor \\ Harsányi \\ Department of Electronics Technology \\ Budapest University of Technology and Economics \\ Budapest, Hungary \\ medgyes@ett.bme.hu
}

\begin{abstract}
The impact of chloride ion concentration on electrochemical migration (ECM) of tin and silver was studied by using an in-situ optical and electrical inspection system. It was found, that in both cases, dendrites grow not only in an electrolyte solution at low chloride concentration but also in an electrolyte at medium and high or even saturated chloride concentrations as well. According to the results, the migration susceptibility has decreased at low and medium concentration levels in both cases. However, the ECM susceptibility of $\mathrm{Ag}$ has increased, while the migration susceptibility of Sn was decreased at the saturated concentrations.
\end{abstract}

Keywords-electrochemical migration; water drop test; $\mathrm{NaCl}$; $\mathrm{Sn}$; $\mathrm{Ag}$.

\section{INTRODUCTION}

Many reliability issues of electronics have to be solved nowadays [1-3]. One of the most dangerous ones is the electrochemical migration (ECM) failure phenomenon.

ECM may cause a relative high reliability risk regarding electronics applications [4]. This failure phenomenon occurs at the presence of humidity in the case of operating circuits: the dissolution of metal traces begins at the anode and produces metal ions, which are directed by the applied electric field and move to the cathode, where they can reduce as pure metals - dendrites (See Fig. 1). Dendrite growth can lead to bridging. Many types of the metals, which are widely used in the electronics industry have huge ability for ECM, such as $\mathrm{Sn}, \mathrm{Ag}$ or $\mathrm{Cu}$ [5]. Silver is also widely investigated related to ECM [5-10].

Usually, migration tests were tested by three main methods; water drop (WD) test [11], environmental tests under different thermal-humidity conditions [12] and by various electroanalytical methods, like voltammetry or polarization tests [13]. On the one hand the electrochemical corrosion and migration investigations of $\mathrm{Ag}$ were usually tested in bulk solution. On the other hand, migration tests in thin electrolyte layers (TEL) is also important, since ECM ability depends on the thickness of water layer as well [14]. Furthermore, the concentrations of the used electrolytes had a wide range as well: deionized water [5], acidic or alkaline electrolytes [15] and also salt electrolytes [16], which usually simulate the possible contamination effects. One of the most common contaminant is the $\mathrm{Cl}$, which can strongly modify the electrochemical corrosion mechanism and therefore, the migration ability of tin and silver as well. Tin and silver ions can combine with hydroxide groups and also with $\mathrm{Cl}^{-}$ions and form complexes in aqueous solutions [4, 17]. The impact of chloride ion on Sn and Ag ECM behavior was already investigated at low concentrations [17, 18].

Although the impact of $\mathrm{NaCl}$ on ECM was already investigated at low concentration, the effect of other concentrations of chloride ion was not reported related to the ECM of tin and silver. Therefore, the migration behavior of Sn and Ag modified by chloride ion is not well understood. So, in this study, different concentrations of $\mathrm{NaCl}$ solution were applied in order to investigate the impact of $\mathrm{Cl}^{-}$concentration on migration in terms of galvanic tin and immersion silver as widely used surface finishes in the electronics.

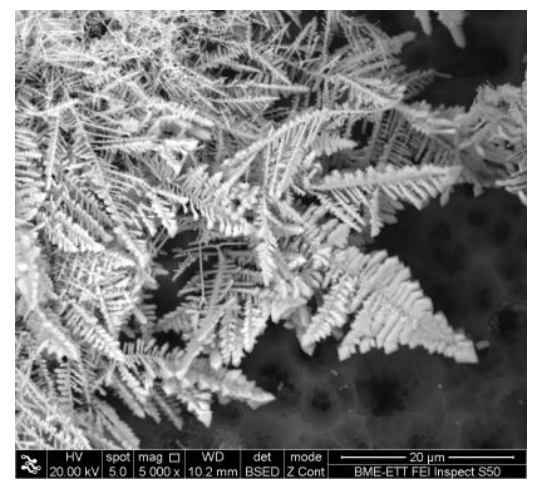

Fig. 1. Scanning electron microscope (SEM) image of dendrites 


\section{EXPERIMENTAL}

In order to simulate the impact of chloride ion on ECM in the case of silver, a pure copper layer was immersed with silver (iAg). In the case of tin, electroplated method was used on copper and both of the surface finishes were fabricated according to the conventional PCB technology. The dimensions of the patterns were $2 \times 5 \mathrm{~mm}$, which structure was prepared on a widely used fiberglass epoxy

resin

substrate (FR4). The gap size between the conductor, lines on the sample was $0.5 \mathrm{~mm}$ (See Fig. 2).

The schematic of the measuring platform can be seen in Fig. 3. The system can follow the various electrochemical migration mechanisms by visual means and by real-time voltage measurements as well. Simultaneously, the ECM mechanisms were in-situ observed by using a USB microscope (type: XCAM MAN1001-SA) for visual inspection and real-time voltage measurement (Novus Automation MyPCLab 6014) was also applied to better understand (verify) the optical results. The real-time voltage measurement is characteristic for the dendrite growth (Since the dendrite grows as a function of time, the voltage increases also as a function of time, simultaneously). The voltage was measured on a serially connected $10 \mathrm{M} \Omega$ resistor, which is located on the negative pole of the test board (See Fig. 3.), while the optical part provides qualitative information, for example about the dendrite structures, growing directions, different residue formations, (out)gassing, etc.

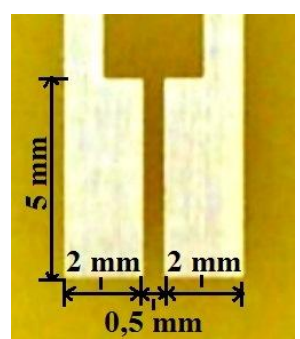

Fig. 2. An iAg test board for ECM test.



Fig. 3. Schematic of the measuring platform for ECM investigation.

Before every water drop (WD) test, the Sn and Ag samples were washed out with deionized water $(2 \mu \mathrm{S} / \mathrm{cm})$, degreased with IPA, and dried in room temperature. The test solution was $\mathrm{NaCl}$ with different concentrations $(0.1 \mathrm{mM}, 1 \mathrm{mM}, 10 \mathrm{mM}, 500 \mathrm{mM}$ and saturated $\mathrm{NaCl}$ ), which was made from deionized water and from analytical grade reagents. The droplets (volume was $25 \mu 1$ in case of $\mathrm{Sn}$ and $15 \mu \mathrm{l}$ in case of Ag due to the different surface wetting behaviour) were placed by a micropipette onto and between the Sn and Ag electrode surfaces. A bias of 3 VDC was used between anode and cathode. At least eight times were all WD test repeated to check reproducibility. The Mean-Time-To-Failure (MTTF) was also calculated from the real-time voltage measurements, where the failure criterion was the first "voltage jump" (see Fig 4). To investigate the chemical compositions of the dendrites and residues, (SEM)-EDS method was also applied. 


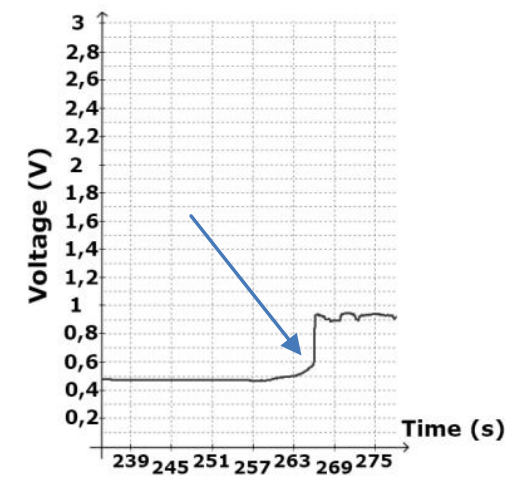

Fig. 4. Failure criterion (Voltage jump) for MTTF calculation.

\section{RESULTS AND DISCUSSION}

A. ECM of $\mathrm{Ag}$ and Sn in $0.1 \mathrm{mM} \mathrm{NaCl}$ solution

In this case, different colored and shaped dendrite formation occurred during the WD test. Furthermore, the dendrite formation was very rapid in both cases; MTTF was about $28 \mathrm{sec}$ in case Ag and $72 \mathrm{sec}$ in case of Sn. A typical optical result can be seen in Fig. 5 for silver, where mainly $\mathrm{Cu}$ was the dominant migration element. Only the red type of dendrite showed some Ag composition according to EDS results (See Fig 5).

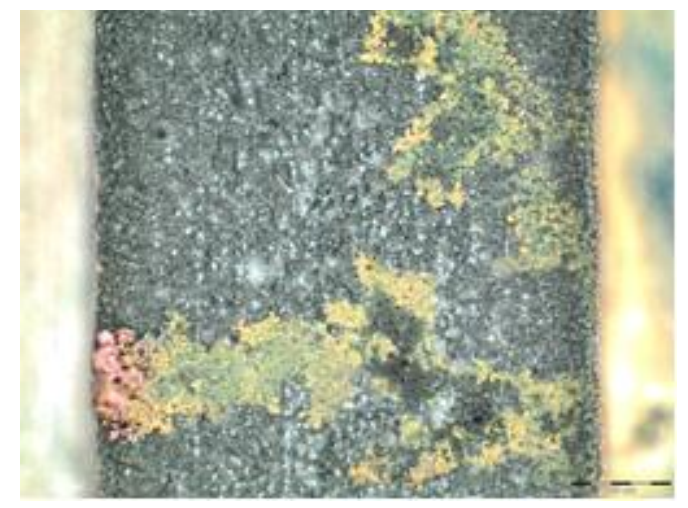

Fig. 5. Different colored dendrites (red, yellow, green) were formed in $0.1 \mathrm{mM} \mathrm{NaCl}$ solution during WD test in case of iAg sample.

In Figure 6, a typical needle-like dendrites and blue colored residues can be seen in case of Sn.

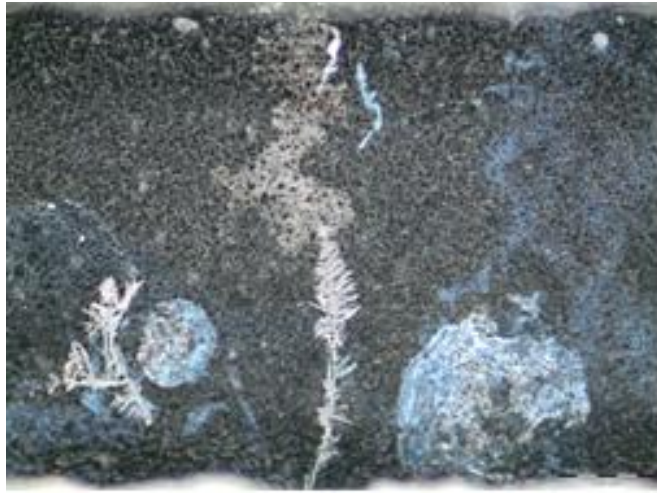

Fig. 6. Dendrites and blue colored resideus were formed in $0.1 \mathrm{mM} \mathrm{NaCl}$ solution during WD test in case of Sn sample.

\section{B. ECM of Ag and Sn in $1 \mathrm{mM} \mathrm{NaCl}$ solution}

At this concentration level very similar results were obtained in case of Ag compare to $0.1 \mathrm{mM}$ level. That means the MTTF, the colors of the formed dendrites and residues did not show any significant differences. However, in case of Sn, the dendrite growth was more dense (see Fig. 7) and the MTTF (around $113 \mathrm{sec}$ ) was also different compare to $0.1 \mathrm{mM}$ level. 


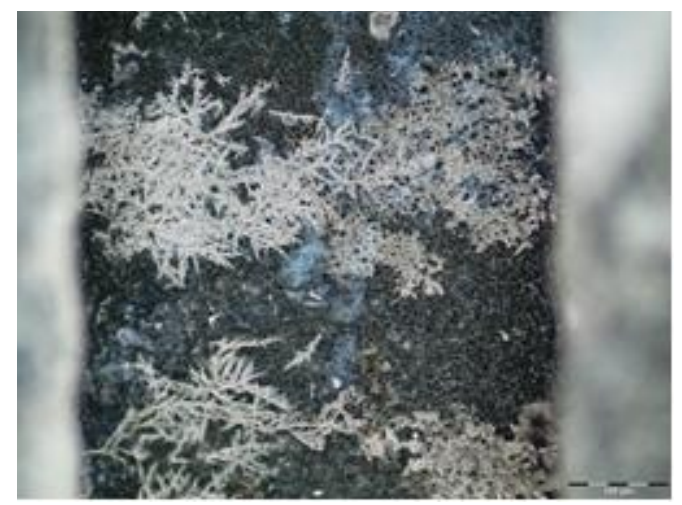

Fig. 7. Dendrite and blue colored residues formed in $1 \mathrm{mM} \mathrm{NaCl}$ solution during WD test in case of Sn sample.

\section{ECM of $\mathrm{Ag}$ and Sn in $10 \mathrm{mM} \mathrm{NaCl}$ solution}

In both cases the ECM susceptibility was significantly decreased. In case of silver, a pale-blue residue wall was formed (Fig. 8), while in case of tin, white colored residue wall was occurred (Fig. 9). However, in all cases dendrite formation was also detected $\left(\mathrm{MTTF}_{\mathrm{Ag}} \sim 783 \mathrm{sec} ; \mathrm{MTTF}_{\mathrm{Sn}} \sim 195 \mathrm{sec}\right)$.

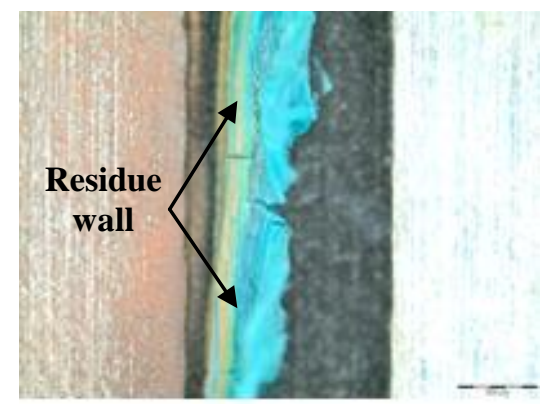

Fig. 8. Blue colored residue was formed in $10 \mathrm{mM} \mathrm{NaCl}$ solution during $\mathrm{WD}$ test in case of immersion $\mathrm{Ag}$.



Fig. 9. White colored residue and dendrites were formed in $10 \mathrm{mM} \mathrm{NaCl}$ solution during WD test in case of galvanic $\mathrm{Sn}$.

In case of immersion silver the dominant migration element was copper in the dendrites as well as in the residues. According to the EDS results and the literature [20], the formed blue residue is $\mathrm{Cu}(\mathrm{OH})_{2}$ with all likelihood.

Despite of the huge white residue wall some dendrite formation can be detected in case of galvanic tin (Fig. 9), which result is similar to the literature [21]. Namely, in [21] only a huge residue wall was occurred with no dendrites. The difference between the current results and [21] can lead back to the different electrolyte thicknesses. According to the EDS results the dominant migration element is $\mathrm{Sn}$ in the dendrites as well as in the residues. The residue is probably $\mathrm{Sn}(\mathrm{OH})_{2}$ or $\mathrm{Sn}(\mathrm{OH})_{4}$.

\section{ECM of $\mathrm{Ag}$ and $\mathrm{Sn}$ in $500 \mathrm{mM} \mathrm{NaCl}$ solution}

In this case of Ag the MTTF value (about $2133 \mathrm{sec}$ ) was significantly increased. In the most cases after evaporation of the bulk solution a thin electrolyte layer (TEL) was remained, where and when the short was occurred. So, this is also a confirmation for the impact of electrolyte layer thickness on the ECM. In Fig. 10 a short can be seen, formed under TEL after evaporation of the bulk solution. 




Fig. 10. Dendrites formed in 500mM NaCl TEL during WD test in case of immersion silver.

After applying the test voltage (3 VDC) gas evolution $\left(\mathrm{H}_{2}\right)$ was occurred, simultaneous with the red-orange colored product formation at the cathode side. This product formed parallel with the electrodes (like a wall) and migrated towards anode. Later, dendrite formation was started from the cathode, which was probably hindered by a green-yellow colored residue wall on the anode (Fig. 10). Finally, after evaporation of the bulk solution either new dendrites were grown or the existing ones found ways to form short across the medium (Fig. 10). According to the EDS results copper was the dominant element in the dendrites as well as in the different colored (red-orange, green) products. The red-orange product is probably $\mathrm{Cu}_{\mathrm{x}} \mathrm{O}(\mathrm{x}=1,2)$ and the green-yellow residue is probably $\mathrm{CuCl}_{2}-3 \mathrm{Cu}(\mathrm{OH})_{2}$, [22]. The supposed chemical states are based on the color, EDS and literature information [22].

In case of tin, there was no significant change compare to the $10 \mathrm{mM}$ case. It means, the value of MTTF, the density and the structure of the dendrites were similar as well as the white residue wall, which is probably $\mathrm{Sn}(\mathrm{OH})_{2}$ or $\mathrm{SnCl}_{2}$.

\section{E. ECM of $\mathrm{Ag}$ and $\mathrm{Sn}$ in saturated $\mathrm{NaCl}$ solution}

On the one hand, the migration susceptibility of silver was dramatically increased (MTTF $\sim 218$ sec), which was an unexpected result. During the electrochemical processes very intensive $\mathrm{H}_{2}$ gassing on the cathode and metal dissolution (discoloration) on the anode was observed (See Fig. 11).

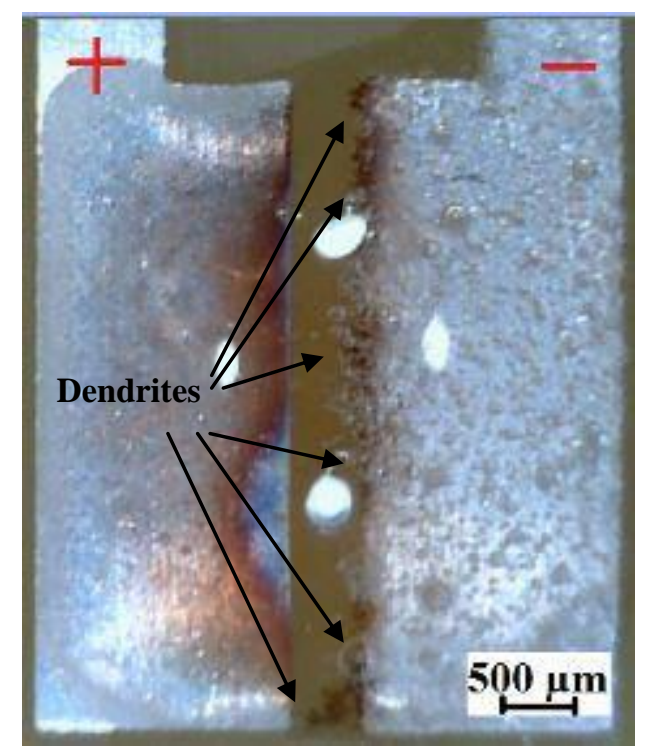

Fig. 11. Short in case of Ag during WD test using saturated $\mathrm{NaCl}$ solution.

It can be also observed that the dendrite growth showed a relative homogeny distribution along the cathode border line (Fig. 11). There was no or less residue formation, which can confirm the low MTTF values (high susceptibility of ECM). It should be also noted, that the shape of the dendrites was very similar compare to the ones, which grown at low NaCl levels. The summarized MTTF values of Ag can be seen in Fig. 12. 


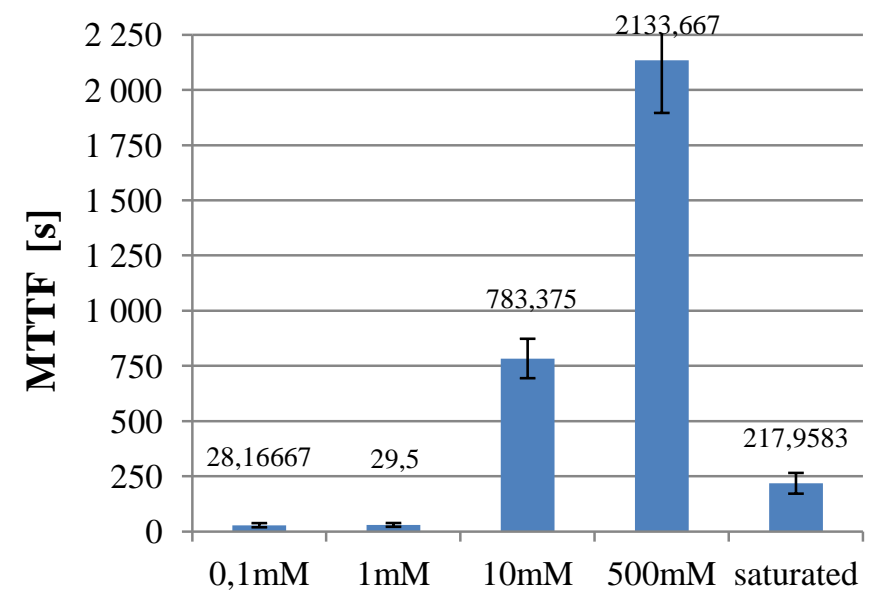

Fig. 12. MTTF values of $\mathrm{Ag}$ in different $\mathrm{NaCl}$ concantrations after WD test.

In case of tin the tendency of ECM ability was not changed (MTTF $363 \mathrm{sec}$ ). The summarized MTTF values of Sn are presented in Fig. 13.

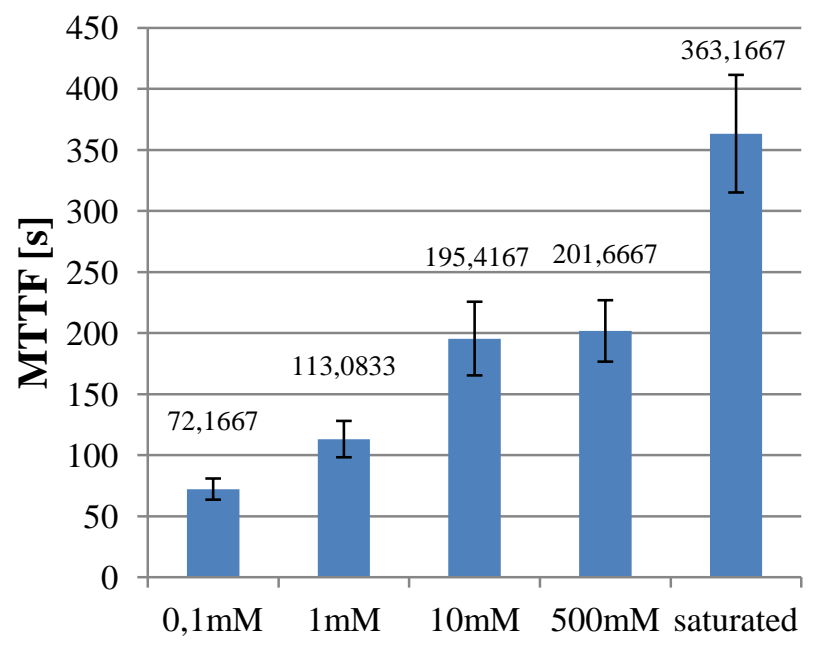

Fig. 13. MTTF values of $\mathrm{Sn}$ in different $\mathrm{NaCl}$ concantrations after WD test.

\section{CONCLUSIONS}

The impact of chloride ion concentration on the electrochemical migration of Ag and Sn was tested by using an in-situ visual and electrical inspection platform under various $\mathrm{NaCl}$ concentrations: $0.1 \mathrm{mM} ; 1 \mathrm{mM} ; 10 \mathrm{mM} ; 500 \mathrm{mM}$ and saturated solution.

In case of immersion silver the followings were found:

- MTTF ranking: $0.1 \mathrm{mM} \leq 1 \mathrm{mM}<$ saturated $\mathrm{NaCl}$ solution $<10 \mathrm{mM}<500 \mathrm{mM}$

- According to the EDS results the dominant migration element was the copper in the dendrites as well as in the residues.

- At the low and at the saturated concentration levels no or less residues were formed, while at the $10 \mathrm{mM}$ and $500 \mathrm{mM}$ $\mathrm{NaCl}$ levels different colored products and residues were observed probably $\mathrm{Cu}(\mathrm{OH})_{2}$ at $10 \mathrm{mM}$ and $\mathrm{CuO} /\left[\mathrm{CuCl}_{2}-\right.$ $\left.\left.3 \mathrm{Cu}(\mathrm{OH})_{2}\right)\right]$ at $500 \mathrm{mM} \mathrm{NaCl}$.

- The relative low MTTF value in case of saturated $\mathrm{NaCl}$ solution was an unexpected result. It can be explained by the relative less residue formation. 
In case of galvanic tin the followings were found:

- MTTF ranking: $0.1 \mathrm{mM}<1 \mathrm{mM}<10 \mathrm{mM} \leq 500 \mathrm{mM}<$ saturated $\mathrm{NaCl}$ solution

- According to the EDS results the dominant migration element was the tin in the dendrites as well as in the residues.

- At low concentration levels blue and white residues were formed (probably $\mathrm{Sn}(\mathrm{OH})_{2}$ was formed at $10 \mathrm{mM} \mathrm{NaCl}$ ). White residues were mainly formed at $500 \mathrm{mM}$ and at saturated $\mathrm{NaCl}$ levels (Probably $\mathrm{SnCl}_{2}$ was occurred).

\section{ACKNOWLEDGMENT}

The work reported in this paper was supported by the János Bolyai Research Scholarship of the Hungarian Academy of Sciences. The authors would like to thank to the Pro Progressio Fundation (Hungary) for the financial support as well.

\section{REFERENCES}

[1] O. Krammer, "Comparing the Reliability and Intermetallic Layer of Solder Joints prepared with Infrared and Vapour Phase soldering", Soldering and Surface Mount Technology, Vol. 26, Issue 4., pp. 214-222, 2014.

[2] A. Geczy, M. Fejos and L. Tersztyánszky, "Investigating and compensating printed circuit board shrinkage induced failures during reflow soldering", Soldering \& Surface Mount Technology, Vol 27. issue 2. pp. 61-68, 2015.

[3] B. Horváth, B. Illés, T. Shinohara, G. Harsányi, "Copper-Oxide Whisker Growth on Tin-Copper Alloy Coatings Caused by the Corrosion of Cu6Sn5 Intermetallics", Journal of Materiaé Science, Vol. 48 pp. 8052-8059, 2013.

[4] D. Minzari, F. B. Grumsen, M. S. Jellesen, P. Møller, R. Ambat, "Electrochemical migration of tin in electronics and microstructure of the dendrites", Corrosion Science, Vol. 53, pp. 1659-1669, 2011.

[5] B. Medgyes, B. Illés, G. Harsányi, "Electrochemical migration behaviour of Cu, Sn, Ag and Sn63/Pb37. ", Journal of Materials Science: Materials in Electronics, Vol. 23, pp. 551-556, 2012.

[6] B. I. Noh, J-B Lee and S-B Jung, "Effect of surface finish material on printed circuit board for electrochemical migration", Microeletronics Reliability, Vol. 48, pp. 652-656, 2008.

[7] S. Yang and A. Christou, "Failure Model for Silver Electrochemical Migration", IEEE TRANSACTIONS ON DEVICE AND MATERIALS RELIABILITY, Vol. 7, No. 1, pp. 188-196, 2007.

[8] S. Yanga, J. Wua and A. Christou, "Initial Stage of Silver Electrochemical Migration Degradation", Microelectronics Reliability, Vol. 46, pp. 1915-1921, 2006.

[9] B.I. Noh, J.W. Yoon, K.S. Kim, Y.C. Lee and S.B. Jung, "Microstructure, Electrical Properties and Electrochemical Migration of a Directly Printed Ag Pattern", Journal of Electronic Materials, Vol. 40, No. 1, pp. 35-41, 2011.

[10] K. S. Kim, Y. T. Kwon, Y. H. Choa and S. B. Jung, "Electrochemical migration of Ag nanoink patterns controlled by atmospheric-pressure plasma", Microelectronic Engineering, Vol. 106, pp. 27-32, 2013.

[11] B. I. Noh, J. W. Yoon, W.S. Hong, S.B. Jung, "Evaluation of Electrochemical Migration on Flexible Printed Circuit Boards with Different Surface Finishes", Journal of Electronic Materials, Vol. 38, No. 6, pp. 902-907, 2009.

[12] B. Medgyes, B. Illés, Richárd Berényi and G. Harsányi, "In situ optical inspection of electrochemical migration during THB tests", Journal of Materials Science: Materials in Electronics, Vol. 22, pp. 694-700, 2011.

[13] G. Harsányi, G. Inzelt, "Comparing migratory resistive short formation abilities of conductor systems applied in advanced interconnection system", Microelectronics Reliability, Vol. 41, pp. 229-237, 2001.

[14] X. Zhong, G. Zhang, X. Guo, "The effect of electrolyte layer thickness on electrochemical migration of tin", Corrosion Science, Vol. 96, pp. 1-5, 2015.

[15] O. Devos, C. Gabrielli, L. Beitone, C. Mace, E. Ostermann, H. Perrot, "Growth of electrolytic copper dendrites. II: Oxalic acid medium", Journal of Electroanalytical Chemistry, Vol. 606, pp. 85-94, 2007.

[16] B. Medgyes, L. Gál, D. Szivós, "The effect of $\mathrm{NaCl}$ on water condensation and electrochemical migration", In: IEEE, 20 ${ }^{\text {th }}$ International Symposium for Design and Technology in Electronic Packaging (SIITME). Bucarest, Romania, pp. 259-262, 2014.

[17] K-K. Ding, X-G. Li, K. Xiao, C-F. Dong, K. Zhang, R-T. Zhao, "Electrochemical migration behavior and mechanism of PCB-ImAg and PCB-HASL under adsorbed thin liquid films", Trans. Nonferrous Met. Soc. China, Vol. 25, pp. 2446-2457, 2015.

[18] V. Verdingovas, M. S. Jellesen and R. Ambat, "Influence of sodium chloride and weak organic acids (flux residues) on electrochemical migration of tin on surface mount chip components", Corrosion Engineering, Science and Technology, Vol. 48. pp. 426-435, 2013.

[19] M. Pourbaix, Atlas of Electrochemical Equilibria in Aqueous Solution, Pergamon Press, Oxford, 1966.

[20] B. Medgyes, X. Zhong, G. Harsányi, "The effect of chloride ion concentration on electrochemical migration of copper", J Mater Sci: Mater Electron, Vol. 26, pp. 2010-2015, 2015.

[21] X. Zhong, G. Zhang, Y. Qiu, Z. Chen, W. Zou, X. Guo, "In situ study the dependence of electrochemical migration of tin on chloride", Electrochemistry Communications, Vol. 27, pp. 63-68, 2013.

[22] A.G. Masey, N.R. Thompson, B.F.G. Johnson, R. Davis, "The Chemistry of COPPER, SILVER and GOLD", Pergamon Press, New York, 1975. 